(C) 2022, The Authors. Published by Elsevier Inc. and Fass Inc. on behalf of the American Dairy Science Association ${ }^{\circledR}$. This is an open access article under the CC BY license (http://creativecommons.org/licenses/by/4.0/).

\title{
The effect of environmental temperature on average daily gain in preweaned calves: A randomized controlled trial and Bayesian analysis
}

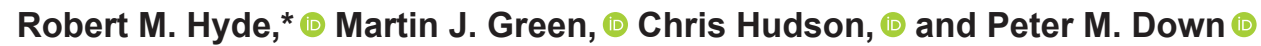

School of Veterinary Medicine and Science, University of Nottingham, Sutton Bonington Campus, Leicestershire, United Kingdom LE12 5RD

\begin{abstract}
Neonatal calves are relatively susceptible to heat loss, and previous research suggests that reduced environmental temperatures are associated with reduced average daily gain (ADG) during the preweaning phase. Current methods of mitigating negative effects of colder environmental conditions include the use of calf jackets and the provision of supplementary heat sources; however, previous research is limited. The aim of this study was to evaluate the effect of calf jackets and 1-kW heat lamps on the growth rates of preweaning calves and evaluate associations between environmental temperature and ADG using a Bayesian approach to incorporate both current and previous data. Seventy-nine calves from a single British dairy farm were randomly allocated at birth to 1 of the following 4 groups: no jacket and no heat lamp, heat lamp but no jacket, jacket but no heat lamp, or both heat lamp and jacket between January and April of 2021. Calves were weighed at both birth and at approximately $21 \mathrm{~d}$ of age. Temperature was recorded both inside and outside of the calf building, and in pens both with and without heat lamps using data loggers. To explore the effect of treatment group and environmental temperature on ADG, a fixed effects model was fitted over 1,000 bootstrap samples. The effect of environmental temperature on ADG was further explored within a Bayesian framework that used temperature and ADG data for 484 calves from 16 farms available from a previous trial as prior information. Calves housed under a $1-\mathrm{kW}$ heat lamp had an increased ADG of $0.09 \mathrm{~kg} / \mathrm{d}(95 \%$ bootstrap confidence interval: -0.02 to $0.20 \mathrm{~kg} / \mathrm{d}$ ), and no effect of jacket or interactions between jacket and heat lamp were found. A significant positive association was identified between the mean environmental temperature of the calf building and $\mathrm{ADG}$, with a $1^{\circ} \mathrm{C}$ increase in temperature being associated with a $0.03 \mathrm{~kg} / \mathrm{d}$
\end{abstract}

Received August 24, 2021.

Accepted December 8, 2021.

*Corresponding author: Robert.hyde4@nottingham.ac.uk increase in ADG (95\% bootstrap confidence interval: 0.01 to $0.04 \mathrm{~kg} / \mathrm{d}$ ). Associations between environmental temperature and ADG were further evaluated within a Bayesian framework, and posterior estimates were 0.014 $\mathrm{kg} / \mathrm{d}$ of $\mathrm{ADG}$ per $1^{\circ} \mathrm{C}$ increase $(95 \%$ credible interval: 0.009 to $0.021 \mathrm{~kg} / \mathrm{d})$. This study demonstrated that a 1-kW heat lamp was effective in increasing ADG in calves, and no significant effect of calf jacket on ADG was found. A significant, positive effect of increased pen temperature on calf ADG was identified in this study and was reinforced when including prior information from previous research within a Bayesian framework.

Key words: average daily gain, calf, heat, jacket, temperature

\section{INTRODUCTION}

Neonatal calves are prone to heat loss in cold conditions due to low surface-to-mass ratio and poor insulation (Roland et al., 2016). Unlike adult cattle, neonatal calves are unable to generate heat through ruminal fermentation (Collier et al., 1982). Thermoregulatory mechanisms can take up to 2 mo to develop (Piccione et al., 2003; Roland et al., 2016), meaning calves are particularly susceptible to cold stress during the preweaning phase of life.

Previous studies have suggested that environmental temperatures can play an important role in growth (Shivley et al., 2018; Hyde et al., 2021), morbidity (Urie et al., 2018), and mortality rates (Hyde et al., 2020) of preweaning calves. Some studies have suggested that the ability of calves to adapt to colder environments is dependent upon the availability of adequate nutrition, with calves consuming more starter in colder than warm environments, likely compensating for the increased thermal demand (Nonnecke et al., 2009). Increasing feeding levels in response to colder environments is not uncommon. Reducing heat loss with the liberal provision of deep dry bedding has been advocated (Nordlund, 2008) to reduce the lower critical temperature and eliminate a portion of the additional calorific requirements when housed in cold environments (Lago et al., 2006). In open barns, it is been suggested that mi- 
croenvironments are crucial, including being draft free with adequate bedding (Roland et al., 2016). However, there has been limited research into the specific effects of temperature on ADG or on methods of providing additional warmth for calves.

The use of both calf jackets and supplementary heat sources, such as heat lamps, represent potential methods of providing warmer microenvironments for calves, although few studies have been published evaluating their effectiveness. Previous research into calf jackets found no benefit in terms of ADG or immune function (Earley et al., 2004), with subsequent studies also finding no benefit in ADG (Scoley et al., 2019). Studies exploring the use of heat lamps have found that perinatal calves show a strong preference for heat lamps and may be associated with significant increases in ADG in very early life (Borderas et al., 2009; Bhat et al., 2015). No previous research has examined the potential effects of heat lamp, jackets, and their combination.

A randomized controlled trial (RCT) is a stringent trial design for determining relationships between an intervention and outcome (Sibbald and Roland, 1998). A factorial study design allows for the evaluation of more than 1 intervention within the same RCT (Montgomery et al., 2003) such as the effect of jacket or supplementary heat on ADG.

The aim of this study was to conduct an RCT to assess the effects of calf jacket or supplementary heat on ADG in preweaning calves. A secondary aim was to evaluate associations between environmental temperature and ADG using a Bayesian approach to incorporate both current and previous data.

\section{MATERIALS AND METHODS}

A 550-cow, all-year calving dairy farm in the United Kingdom was recruited by convenience due to a relatively large herd size, geographical location, and history of accurate data recording.

All calves born between January 2, 2021, and April 6, 2021 , were randomly assigned at birth in a $2 \times 2$ factorial design to 1 of the following 4 groups: no jacket, no heat lamp $(\mathbf{C O N})$, heat lamp but no jacket $(\mathbf{H})$, jacket but no heat lamp $(\mathbf{J})$, or both heat lamp and jacket (HJ). The treatment intervention (heat lamp, jacket, or both) was provided immediately after allocation. Randomization was performed using the sample function in R (R Core Team, 2020) and implemented using a set of sealed envelopes containing group allocation for farm staff to open upon calf enrolment. Blinding of the farm staff to jacket or heat lamp usage was not possible. Calves were weighed using a calf weigh crush (Bateman) and weigh scale (Tru-test EZIWEIGH 5) at birth and 14 to $35 \mathrm{~d}$ of age, when beef and bull calves would be sold, and dairy heifer calves were moved to alternate housing. The weigh crush and weigh scale were calibrated every $14 \mathrm{~d}$ using a known weight. Calf identification, breed, sex, and intervention group were recorded alongside birthweight and second weights. All calves born during the trial period were enrolled in the trial, and calves weighed $<14 \mathrm{~d}$ between weights were removed from the data set. Due to the limited number of heat-lamp pens available, animals were excluded from the trial when heat-lamp pens were fully occupied.

Calves were housed in individual pens $(1.4 \mathrm{~m} \times 1.0$ $\mathrm{m})$ with solid sides at $0.9-\mathrm{m}$ height. Pens not under heat lamps were arranged side to side in a row of 15 pens in each of the 4 quarters of the shed. Pens under heat lamps were arranged in a square consisting of 4 pens, with 1 heat lamp being placed over the center of all 4 pens at a height of approximately $1 \mathrm{~m}$ above the bedding (i.e., 1 heat lamp shared across 4 pens). To limit the effect of any potential within-shed variations, 1 group of pens both under heat lamp and not under heat lamps were placed in each of 4 quarters of the shed. Four heat lamps (Kiam) were set at $1 \mathrm{~kW}$ and were left on continuously throughout the trial regardless of environmental temperature. Data loggers (EL-USB-2, LASCAR electronics) were placed in both pens with and without heat lamps at $50-\mathrm{cm}$ height within the calf pen and recorded the environmental temperature every 15 min.

After calving, calves were removed from the dam and fed $4 \mathrm{~L}$ of fresh cow colostrum as soon as possible, and always within $6 \mathrm{~h}$ of birth. A second feed of $2 \mathrm{~L}$ of fresh cow colostrum was fed approximately $6 \mathrm{~h}$ later. Twice daily until $14 \mathrm{~d}$ of age, calves were then fed $3 \mathrm{~L}$ of milk harvested from cows vaccinated with Rotavec Corona (MSD Animal Health) and pasteurized at $60^{\circ} \mathrm{C}$ for 60 min using a pasteurizer (Holm and Laue). Calves were subsequently fed $4 \mathrm{~L}$ of milk replacer powder (Advanced Superstart 23\% CP, 20\% Fat, Advanced Sourcing) twice daily at a concentration of $150 \mathrm{~g} / \mathrm{L}$. Starter pellets (Calf starter 18\% CP, ForFarmers) and fresh water were provided ad libitum to all calves from birth.

\section{Statistical Analysis}

Statistical analysis was performed in $\mathrm{R}$ using the tidyverse collection of packages (Wickham et al., 2019). To determine an appropriate sample size, an a priori sample size calculation was performed using the Size. Full function from the BDEsize package (Chung and $\mathrm{Lim}, 2019)$. To detect a difference of $0.075 \mathrm{~kg} / \mathrm{d}$ in ADG, 17 calves would be required in each of the 4 groups at $80 \%$ power, a significance level set at $P$-value 
$<0.05$, and a standard deviation of $0.15 \mathrm{~kg} / \mathrm{d}$, assuming no interactions between treatment groups were present.

Models were fitted on 1,000 bootstrap samples to provide robust estimates of both coefficients and model performance, including $95 \%$ bootstrap confidence intervals (BCI) calculated using lower and upper coefficient quantiles of 2.5 and $97.5 \%$ across bootstrap samples respectively, using the tidymodels collection of packages (Kuhn and Wickham, 2020). The coefficients of determination for fixed effects models were calculated using the broom package (Robinson et al., 2021). Bootstrap $P$-values were calculated as 1 minus the proportion of coefficient estimates on the majority side of zero. Variables with a bootstrap $P$-value $<0.05$ were deemed to have a high probability of having an effect size $>$ or $<0$. The marginal (variation in pen temperature explained when excluding the random effect of logger identification) and conditional (variation in pen temperature explained when including the random effect of logger) coefficients of determination for mixed effects models were calculated using the MuMIn package (Barton, 2020). Residuals were checked after a model was fitted on the full data set (i.e., without bootstrap resampling) for near normal distribution (Dohoo et al., 2009).

\section{Associations Between Treatment Group and Environmental Temperature and ADG}

To explore the effect of treatment group (CON, J, H or $\mathrm{HJ}$ ) on ADG, a fixed effects linear regression model was fitted, and model parameters were estimated using 1,000 bootstrap samples. The model took the following form:

$Y_{i}=\mu+\beta_{1} X_{1 i}+\beta_{2} X_{2 i}+\beta_{3} X_{1 i} X_{2 i}+\beta_{4} X_{4 i}+\beta_{5} X_{5 i}+\varepsilon$,

where $Y_{i}$ was the ADG of the $i$ th calf. The coefficients were represented by $\beta_{1}$ for jacket usage, $\beta_{2}$ for heat lamp usage, and $\beta_{3}$ as an interaction term between jacket and heat lamp usage; $\beta_{4}$ represented mean outside temperature $\left({ }^{\circ} \mathrm{C}\right)$ and $\beta_{5}$ breed; $\mu$ represented the intercept; and $\varepsilon$ represented the residual model error. The assumed distribution of $\varepsilon$ was normal, with mean zero and variance $\theta$.

\section{Bayesian Approach to Associations Between Pen Temperature and ADG}

Associations between environmental temperature and ADG were further explored using a Bayesian approach. Prior information was obtained from previous trial data (Hyde et al., 2021) including 484 calves from
16 farms with both ADG calculated from 2 weigh tape measurements and temperature data for every day of life between these 2 dates. The effect of temperature on ADG was estimated using a mixed effects model as follows:

$$
Y_{i j}=\mu+\beta_{1} X_{1 i j}+U_{j}+\varepsilon_{i j},
$$

where $Y_{i j}$ was the ADG of the $i$ th calf on the $j$ th farm; $\beta_{1}$ represented the coefficient for the effect of environmental temperature between birth and weaning on ADG for the $i$ th calf on the $j$ th farm; $\mu$ represented the intercept; $U_{j}$ represented the random effect of logger; and $\varepsilon_{i j}$ represented the random error. The assumed distribution of $U_{j}$ and $\varepsilon_{i j}$ was normal, with mean zero and variance $\theta U$ and $\theta \varepsilon$, respectively. The distribution of $\beta_{1}$ was used as a prior for a Bayesian model, such that the posterior was the joint probability distribution combining the prior and likelihood and for the outcome ADG (Muth et al., 2018). Markov chain Monte Carlo chains were used, with 3 chains and over 10,000 iterations with the first 1,000 discarded as warm up using the rstanarm package (Goodrich et al., 2020). Chains were visually checked for convergence, and posterior predictive checks over 100 repeats were conducted to ensure distributions of simulated data were analogous to the real data. Credible intervals $(95 \%)$ were calculated using the posterior_interval function, and coefficient of determination was calculated using the bayes_R2 function within the rstanarm package (Goodrich et al., 2020) based on Gelman et al. (2019).

\section{Effect of Heat Lamp on Pen Temperature}

To explore the effect of heat lamp usage on mean daily pen level temperature, a mixed effects model with data logger included as a random effect was built and model parameters estimated using 1,000 bootstrap samples. The model took the following form:

$$
Y_{i j}=\mu+\beta_{1} X_{1 i j}+\beta_{2} X_{2 i j}+U_{j}+\varepsilon_{i j},
$$

where $Y_{i j}$ was the mean daily temperature of the $i$ th day for the $j$ th data logger. The coefficient was represented by $\beta_{1}$ for the mean daily outside temperature and $\beta_{2}$ for heat lamp use as a binary categorical variable; $\mu$ represented the intercept; $U_{j}$ represented the random effect of logger; and $\varepsilon_{i j}$ the residual error. The assumed distribution of $U_{j}$ and $\varepsilon_{i j}$ was normal, with mean zero and variance $\theta U$ and $\theta \varepsilon$, respectively.

The study was conducted following ethical approval from the University of Nottingham Committee for Animal Research and Ethics (3281 201116). 
Table 1. Descriptive results of weights, ages, and ADG by treatment group for 79 dairy calves randomly assigned at birth in a $2 \times 2$ factorial design to 1 of 4 groups as follows: no jacket, no heat lamp; heat lamp but no jacket; jacket but no heat lamp; or both heat lamp and jacket

\begin{tabular}{|c|c|c|c|c|c|}
\hline Group & $\begin{array}{l}\text { Number of calves } \\
\text { (female/male) }\end{array}$ & $\begin{array}{l}\text { Mean ADG } \\
(\mathrm{kg} / \mathrm{d})\end{array}$ & $\begin{array}{c}\text { Mean age at second } \\
\text { weight }(\mathrm{d})\end{array}$ & $\begin{array}{l}\text { Mean weight at } \\
\text { birth }(\mathrm{kg})\end{array}$ & $\begin{array}{l}\text { Mean weight at } \\
\text { second weight }(\mathrm{kg})\end{array}$ \\
\hline No lamp, no jacket & $23(8 / 15)$ & 0.57 & 21 & 46.53 & 58.09 \\
\hline Lamp and jacket & $17(9 / 8)$ & 0.64 & 19 & 43.15 & 55.48 \\
\hline
\end{tabular}

\section{RESULTS}

A total of 117 calves were enrolled with both a birthweight and 14- to 35-d weight between January 2, 2021, and April 6, 2021. Ear tag recording errors were made when recording birth weights for 3 calves, and these animals were removed from the data set. Heat lamp pens were unavailable for 10 calves that were allocated to the heat lamp group, and these animals were removed from the data set. Twenty-five calves were sold before a second BW measurement had been made and were removed from the data set. Seventy-nine calves were included in the final data set, consisting of 37 female calves and 42 male calves. Calf breed was predominantly Aberdeen Angus cross Holstein Friesian (n $=66)$, with some Holstein Friesian $(\mathrm{n}=8)$ and Belgian Blue cross Holstein Friesian $(\mathrm{n}=5)$, and the distribution of both breed and sex across treatment groups was checked to ensure relatively even distribution after random allocation.

A total of 57,182 temperature recordings were taken from 20 data loggers across the study period. For analysis of the effect of heat lamp on pen temperature, there were 323 pen-days available in the final data set. For analysis of associations between treatment group, breed and environmental temperature, and ADG, there were 79 calves with $\geq 14$ d between weights.

Calves were weighed with a mean of $19 \mathrm{~d}(14-33 \mathrm{~d})$ days between weights, and the mean ADG of calves was $0.59 \mathrm{~kg} / \mathrm{d}(\mathrm{SD}=0.18 \mathrm{~kg} / \mathrm{d})$ across all calves, with a mean ADG of $0.57 \mathrm{~kg} / \mathrm{d}=(\mathrm{SD} 0.17 \mathrm{~kg} / \mathrm{d})$ for $\mathrm{CON}$, $0.57 \mathrm{~kg} / \mathrm{d}(\mathrm{SD}=0.18 \mathrm{~kg} / \mathrm{d})$ for $\mathrm{J}, 0.61 \mathrm{~kg} / \mathrm{d}(\mathrm{SD}=0.21$ $\mathrm{kg} / \mathrm{d})$ for $\mathrm{H}$, and $0.64 \mathrm{~kg} / \mathrm{d}(\mathrm{SD}=0.16 \mathrm{~kg} / \mathrm{d})$ for HJ groups, respectively (Table 1 , Figure 1 ). The mean pen temperature was $9.19^{\circ} \mathrm{C}\left(\mathrm{SD}=6.15^{\circ} \mathrm{C}\right)$, and mean daily temperature ranged from $-1.59^{\circ} \mathrm{C}$ to $25.16^{\circ} \mathrm{C}$ (Figure $2)$. The mean temperature of pens with heat lamps was $11.98^{\circ} \mathrm{C}\left(\mathrm{SD}=5.40^{\circ} \mathrm{C}\right.$, range $=3.67^{\circ} \mathrm{C}$ to $\left.25.16^{\circ} \mathrm{C}\right)$ compared with a mean pen temperature of pens without heat lamps of $7.11^{\circ} \mathrm{C}\left(\mathrm{SD}=5.84^{\circ} \mathrm{C}\right.$, range $=-1.59^{\circ} \mathrm{C}$ to $19.20^{\circ} \mathrm{C}$ ). Therefore, the mean daily temperature was $4.9^{\circ} \mathrm{C}$ higher in pens with heat lamps than those with no heat lamps. There was minimal difference between ambient shed and outside temperatures $\left(0.04^{\circ} \mathrm{C}\right)$, consistent with previous findings (Hyde et al., 2021).

\section{Associations Between Treatment Group and Environmental Temperature and ADG}

Results from the final mixed effects model demonstrated that calves housed under heat lamps had a significantly increased ADG $(0.09 \mathrm{~kg} / \mathrm{d}, 95 \%$ BCI = $-0.02-0.20 \mathrm{~kg} / \mathrm{d}$, bootstrap $P$-value $=0.047$, Table 2 , Figure 3) than those without heat lamps. No effect of jacket or any interactions between jacket and heat lamp were found. An association between increased mean environmental temperature and increased ADG was identified, with a $1^{\circ} \mathrm{C}$ increase in building temperature being associated with a $0.03 \mathrm{~kg} / \mathrm{d}$ increase in ADG $(95 \%$ BCI $=0.01-0.04 \mathrm{~kg} / \mathrm{d}$, bootstrap $P$-value $=0.002)$. A significant association between calf breed was also found, with Belgian Blue cross calves growing faster $(0.16 \mathrm{~kg} / \mathrm{d}, 95 \% \mathrm{BCI}=-0.03-0.30 \mathrm{~kg} / \mathrm{d}$, bootstrap $P$-value $=0.036)$ and Holstein Friesian calves growing slower $(-0.16 \mathrm{~kg} / \mathrm{d}, 95 \%$ BCI $=-0.27-0.06$ $\mathrm{kg} / \mathrm{d}$, bootstrap $P$-value $<0.001)$ than the reference breed Angus cross.

\section{Bayesian Approach to Associations Between Pen Temperature and ADG}

Visual description of associations between pen temperature and growth rates for the 16 farms supplying data for the prior distribution and for the current study farm are shown in Figure 4. The prior estimated from the mixed effects model using data from the previous trial was normally distributed (mean $=0.015 \mathrm{~kg} / \mathrm{d}$ and $95 \% \mathrm{CI}=0.008-0.023 \mathrm{~kg} / \mathrm{d}$; increase in $\mathrm{ADG}$ per $1^{\circ} \mathrm{C}$ increase). Likelihood estimates based on weakly informative priors were $0.014 \mathrm{~kg} / \mathrm{d}(95 \% \mathrm{CI}=0.004-0.024$ $\mathrm{kg} / \mathrm{d}$ ) per $1^{\circ} \mathrm{C}$ increase. Posterior estimates were 0.014 $\mathrm{kg} / \mathrm{d}(95 \% \mathrm{CI}=0.009-0.021 \mathrm{~kg} / \mathrm{d})$ per $1^{\circ} \mathrm{C}$ increase, and the median Bayesian coefficient of determination was $0.11(95 \% \mathrm{CI}=0.04-0.20)$. The distributions of prior, likelihood, and posterior estimates are shown in Figure 5. 


\section{Effect of Heat Lamp on Pen Temperature}

Outside environmental temperature and heat lamp usage were both associated with pen temperature, with a $1^{\circ} \mathrm{C}$ increase in outside temperature associated with a $0.99^{\circ} \mathrm{C}$ increase in pen temperature $(95 \%$ BCI $\left.=0.93-1.05^{\circ} \mathrm{C}\right)$, and heat lamp usage associated with a pen temperature increase of $4.73^{\circ} \mathrm{C}(95 \%$ BCI $=$ $\left.4.43-5.01^{\circ} \mathrm{C}\right)$. Bootstrapped mean marginal coefficient of determination was $80 \%(95 \% \mathrm{BCI}=0.75-0.83)$ with a conditional coefficient of determination of $88 \%(95 \%$ $\mathrm{BCI}=0.85-0.91)$.

\section{DISCUSSION}

The results of this RCT suggested that $1-\mathrm{kW}$ heat lamps had a significant positive effect on ADG in preweaning calves, and calf jackets were not significantly associated with ADG. Results also suggested that ADG in calves was significantly associated with environmental temperature. The positive effect of environmental temperature on ADG identified in the current trial was further reinforced when information from previous research was integrated through a Bayesian modeling approach. This represents an important factor for consideration in the improvement of productivity of calves on dairy farms.

Increasing temperatures in calf buildings without supplementary heat input is likely to be extremely challenging, and the current study data suggested that without such heat sources, there would be minimal differences between the internal and external temperature of calf buildings, as found in both the current study and previous studies (Hyde et al., 2021). The use of heat lamps was associated with an increase in pen temperature of $\sim 5^{\circ} \mathrm{C}$, and calves housed under heat lamps in the current study grew at a higher rate than those not housed under a heat lamp. One-kilowatt heat lamps, as used in this study, could be used to improve calf growth rates in Great Britain and would be expected to increase in growth rates in early life by $\sim 90 \mathrm{~g} / \mathrm{d}$ when used in colder months.

Alongside improvements in productivity, previous studies suggest that calves tend to show a preference for heated areas, suggesting there may be a positive welfare aspect to the use of heat lamps (Borderas et al., 2009). Although heat lamps may represent a useful adjunct to improve the ADG of preweaning calves, there are both economic and safety considerations. A 1-kW heater uses $504 \mathrm{kWh}$ per 21-d period. Based on a mean electricity cost of $£ 0.13$ (\$0.19) per kWh in 2020 (UK Government, 2021), the heater would cost $£ 67.74$ (\$94.27) per $21 \mathrm{~d}$ to run if left on constantly. This cost would be split among 4 calves in the current study, at a cost of $£ 16.93$ (\$23.56) per calf. It may be possible to share a heat lamp between a higher number of calves if in a loose housed pen; however, there may be a disease risk if large numbers of calves are crowding underneath a heat lamp, which bears consideration. Further costbenefit analysis would be necessary to determine if the

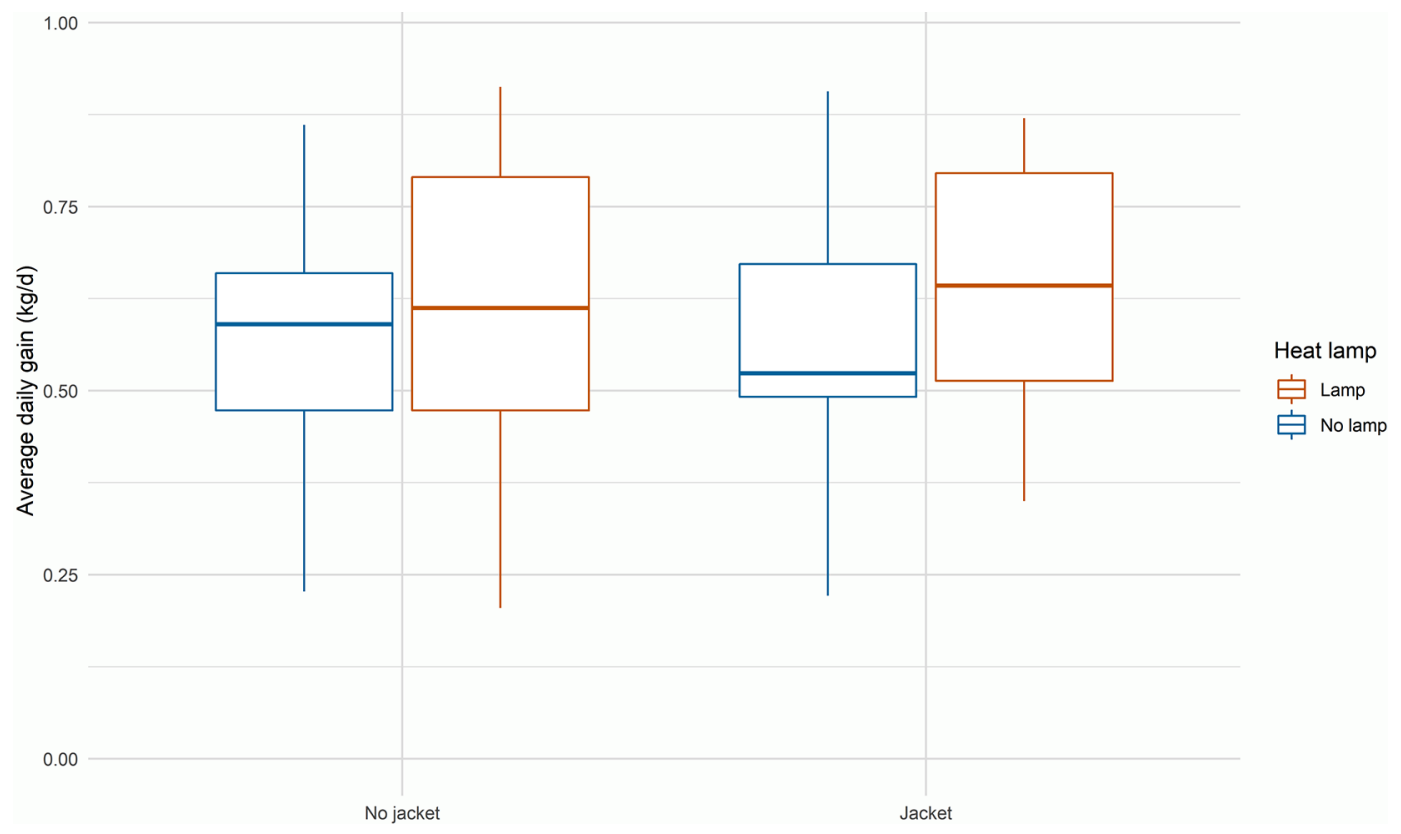

Figure 1. Average daily gain $(\mathrm{kg} / \mathrm{d})$ by intervention group for 79 dairy calves randomly assigned at birth in a $2 \times 2$ factorial design to 1 of 4 groups (boxplots left to right): no jacket and no heat lamp, heat lamp but no jacket, jacket but no heat lamp, or both heat lamp and jacket. 


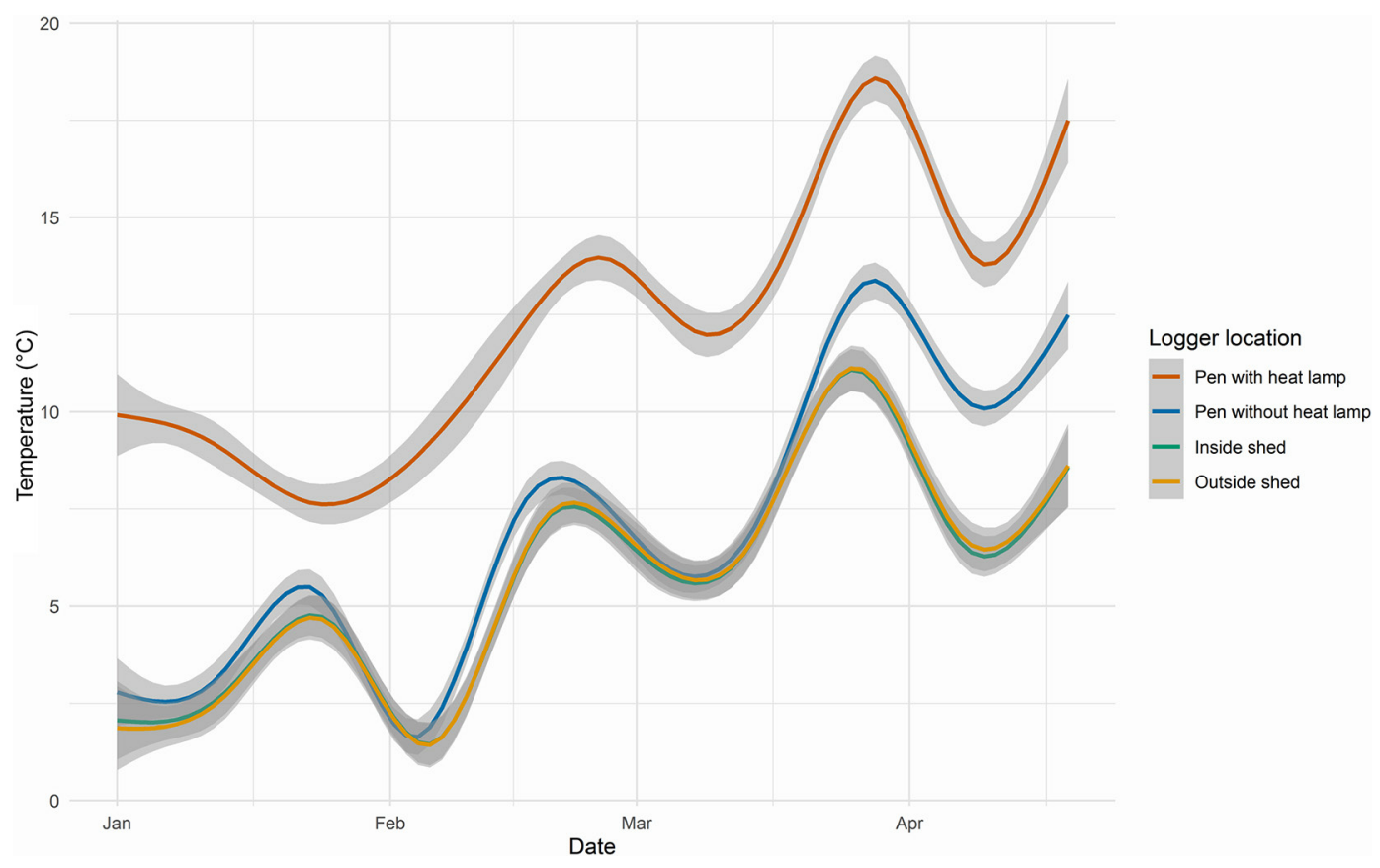

Figure 2. Mean environmental temperature $\left({ }^{\circ} \mathrm{C}\right)$ over time by logger location for data loggers placed in both heat lamp, and non-heat lamp pens as well as both inside and outside the calf shed, recording the environmental temperature every 15 min.

running cost is likely to be a worthwhile investment for the potential increases in ADG. The heaters used in the current trial were left on continuously throughout the trial. However, turning the heater on depending on the ambient temperatures (i.e., only overnight, or only when environmental temperatures drop below a specified level) may result in different levels of improvement in ADG. Other heating schedules would be an interesting area for further study that might reduce the overall cost. The carbon cost of running heat lamps is also worth consideration, although renewable energy generation may mitigate this depending on the electricity source. It is also worth considering the safety aspects of using heaters within livestock buildings. The heat lamps in the current study were supported from steel girders with steel cable to ameliorate the risk of heat lamps being knocked into straw bedding, which could have disastrous consequences.

The type of heater is also likely to be important, and preliminary investigations suggested a more typical 250 -W livestock heat lamp used for lambs or poultry might only provide a $\sim 1^{\circ} \mathrm{C}$ increase compared with the $\sim 5^{\circ} \mathrm{C}$ increase seen with a $1-\mathrm{kW}$ heater suspended above a calf pen at $1 \mathrm{~m}$ above bedding. It is also worth noting that the data loggers used in this trial measured environmental temperature and did not measure direct

Table 2. Linear regression model results of associations between treatment group, breed, and mean environmental temperature, and $\mathrm{ADG}(\mathrm{kg} / \mathrm{d})$ over 1,000 bootstrap repeats for 79 dairy calves randomly assigned at birth in a $2 \times 2$ factorial design to 1 of the following 4 groups: no jacket, no heat lamp; heat lamp but no jacket; jacket but no heat lamp; or both heat lamp and jacket ${ }^{1}$

\begin{tabular}{lcc}
\hline Term & $\begin{array}{c}\text { Mean coefficient } \\
(95 \% \mathrm{BCI})\end{array}$ & Bootstrap $P$-value \\
\hline Intercept & $0.39(0.29-0.50)$ & \\
Breed Blue (reference Angus) & $0.16(-0.03-0.30)$ & 0.036 \\
Breed Holstein (reference Angus) & $-0.16(-0.27-0.06)$ & $<0.001$ \\
Jacket use & $0.04(-0.06-0.14)$ & 0.231 \\
Lamp use & $0.09(-0.02-0.20)$ & 0.047 \\
Lamp-jacket interaction & $-0.05(-0.20-0.11)$ & 0.002 \\
Environmental temperature $\left({ }^{\circ} \mathrm{C}\right)$ & $0.03(0.01-0.04)$ &
\end{tabular}

${ }^{1}$ Mean coefficient of determination was 0.27 [95\% bootstrap confidence interval (BCI): 0.13-0.44]. Coefficient estimations for categorical variables are associated with the change in ADG $(\mathrm{kg} / \mathrm{d})$ associated with the variable compared with the reference category being "no use" for lamp and jacket use and "Angus cross" for breed. 


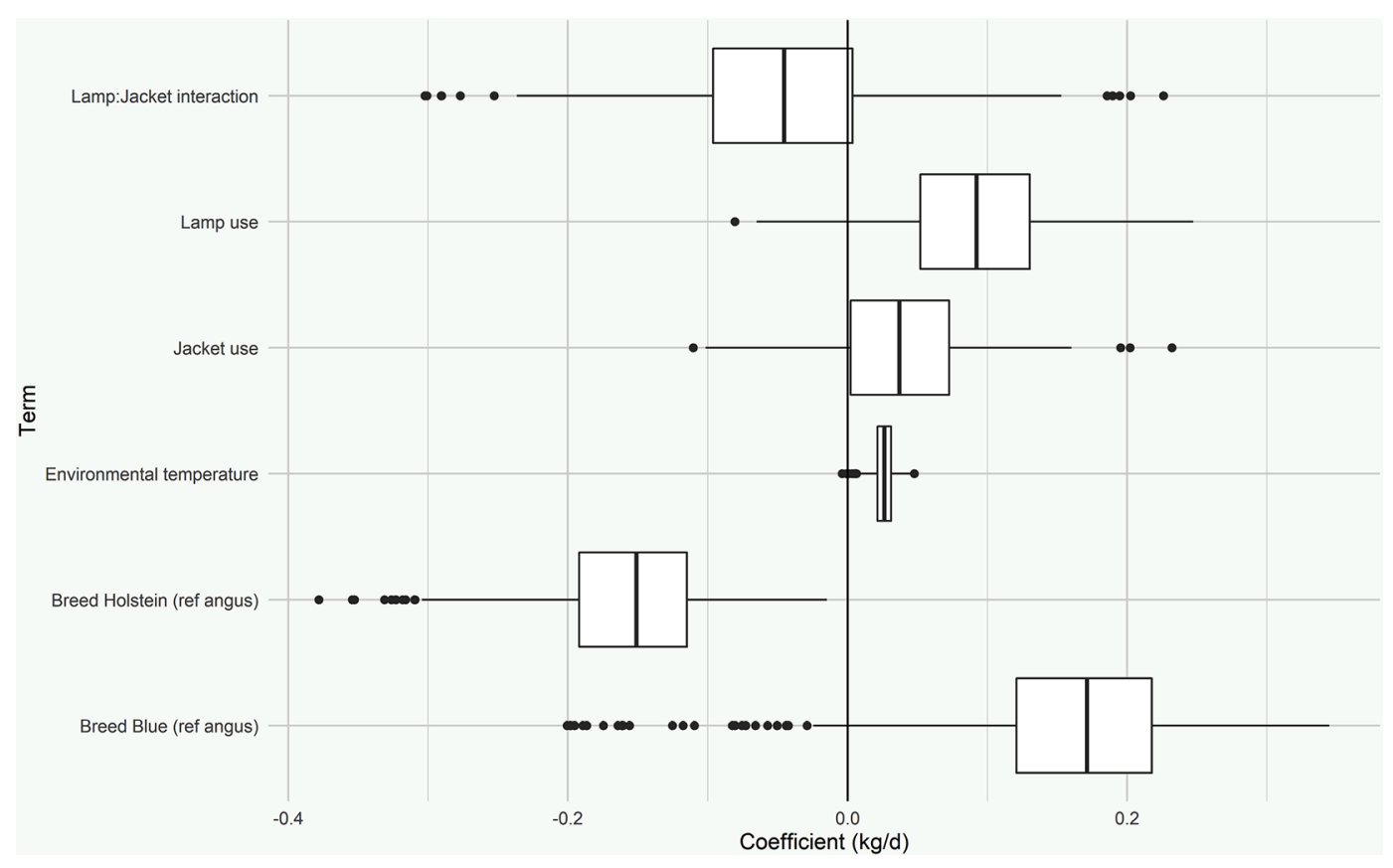

Figure 3. Coefficient distributions for associations with ADG for 79 dairy calves randomly assigned at birth in a $2 \times 2$ factorial design to 1 of 4 groups: no jacket and no heat lamp, heat lamp but no jacket, jacket but no heat lamp, or both heat lamp and jacket. Coefficient estimations for temperature represent the change in $\mathrm{ADG}(\mathrm{kg} / \mathrm{d})$ associated with a $1^{\circ} \mathrm{C}$ change in outside environmental temperature, and coefficient estimations for categorical variables are associated with the change in ADG (kg/d) associated with the variable compared, with the reference category being "no use" for lamp and jacket use and "Angus cross" for breed.

radiant heat as might be measured with a black globe temperature probe. However, increases in temperature under heat lamps compared with no heat lamps as measured by a black globe probe were comparable to those recorded from the data loggers during preliminary investigations. There is a trade-off in calf housing design between maintaining a warm environment for the calves and the provision of fresh air crucial in reducing the risk of respiratory disease (Nordlund, 2008). Although pen temperature appears to be important in calf growth, the pursuit of a warm environment at the expense of adequate ventilation may increase the risk of respiratory disease outbreaks.

As reported in previous studies (Earley et al., 2004; Scoley et al., 2019), jacket usage was not significantly associated with ADG. This finding is consistent with results from previous studies, and despite their relatively common presence on farms, jackets by themselves are unlikely to result in substantial improvements in ADG. It was not possible in the current study to explore physiological reasons why jackets were not effective in improving ADG, but it is possible that the jacket usage is simply not effective enough in mitigating heat loss to detect a measurable improvement in ADG.

The RCT component of the current study was limited to a single UK farm, and caution should be taken with the extrapolation of these results to the wider industry, and particularly to different countries and climates. Calves in this RCT were individually housed, and although previous reports have suggested that calves being physically active might increase heat production and thus cold resistance (Roland et al., 2016), the housing of animals in relatively small pens might hinder the ability of these animals to mitigate cold stress through movement. Similarly, other behavioral adaptations to cold such as crowing or huddling (Roland et al., 2016) would not be possible in individual housing. It was not possible to fully explore the physiological reasons behind higher ADG of calves under heat lamps in this study. However, it is possible that the calves under heat lamps may have been expending less energy in this warmer environment or were more active, and thus consuming higher levels of solid feed, and future studies might explore these areas further. Although breed type was included within models to account for associations between breed and ADG, a limitation of this study was that the further exploration of associations between environmental temperature and ADG for different breed types could not be fully explored in the current study due to limited numbers of calves in breeds other than Angus cross Holstein. Future studies might explore the effect of providing heat lamps on different breed types in more detail. Although the current study focused on environmental temperature, it is possible that other 
environmental factors such as humidity and both airborne bacterial or noxious gas levels might be associated with ADG and could be explored in future studies. One limitation of the current study is the relatively high variability in ADG, which was higher than anticipated when performing the sample size calculations. Increased variability in weights at calf rather than farm level during early life has been reported previously (Archer, 2021). However, due to the commercial practices of the farm in the current study, it was not possible to retain calves for longer periods of time to reduce the variability in ADG and thereby increase the likelihood of finding a significant result. Further work should explore the effect of heat lamps and jackets over a longer period of time to reduce the variability between calves. Analysis of the study population (Table 1) showed more calves did not receive lamps than did receive lamps, and it is possible that farm staff might not have recorded some of the cases when heat lamps were available due to limited numbers. Instead of being removed from the trial, they may have been allocated to a group without heat lamps instead. As allocation to treatment group was random, there were a higher number of male than female calves in the CON group and slightly more female calves than male calves in the $\mathrm{H}$ group (Table 1). Due to the necessity of sharing 1 heat lamp between 4 pens, there were differences in pen arrangement for calves under heat lamps (block of
4 pens) and those not under heat lamps (row of pens). Even though it is possible that this difference may have had some effect on the trial results, the authors feel this risk was relatively small. Analysis of the effect of treatment group on morbidity and mortality levels would be interesting in future studies; however, the sample size required for a binary, relatively low incidence outcome was far in excess of the available calf numbers in this instance. Cases of disease are likely to negatively affect ADG (Windeyer et al., 2014), and larger trials may be able to further explore both the effect of treatment group on morbidity and mortality levels in addition to any associations between morbidity and ADG.

A Bayesian approach allowed the incorporation of both information excluding the trial data (prior) and current data (likelihood) to form a final estimate (posterior) of an association between a variable and a given outcome (Spiegelhalter et al., 2004). The accuracy of an estimate of associations between environmental temperature and ADG is likely to be improved when incorporating both the data from the current trial and data from previous research (Hyde et al., 2021) in a Bayesian framework. Growth rates in early life are likely to be multifactorial. Although this study focused primarily on the effects of environmental temperature on ADG, there are several other factors around stocking demographics, milk or colostrum feeding, and environmental hygiene that are likely to be important (Hyde et al.,

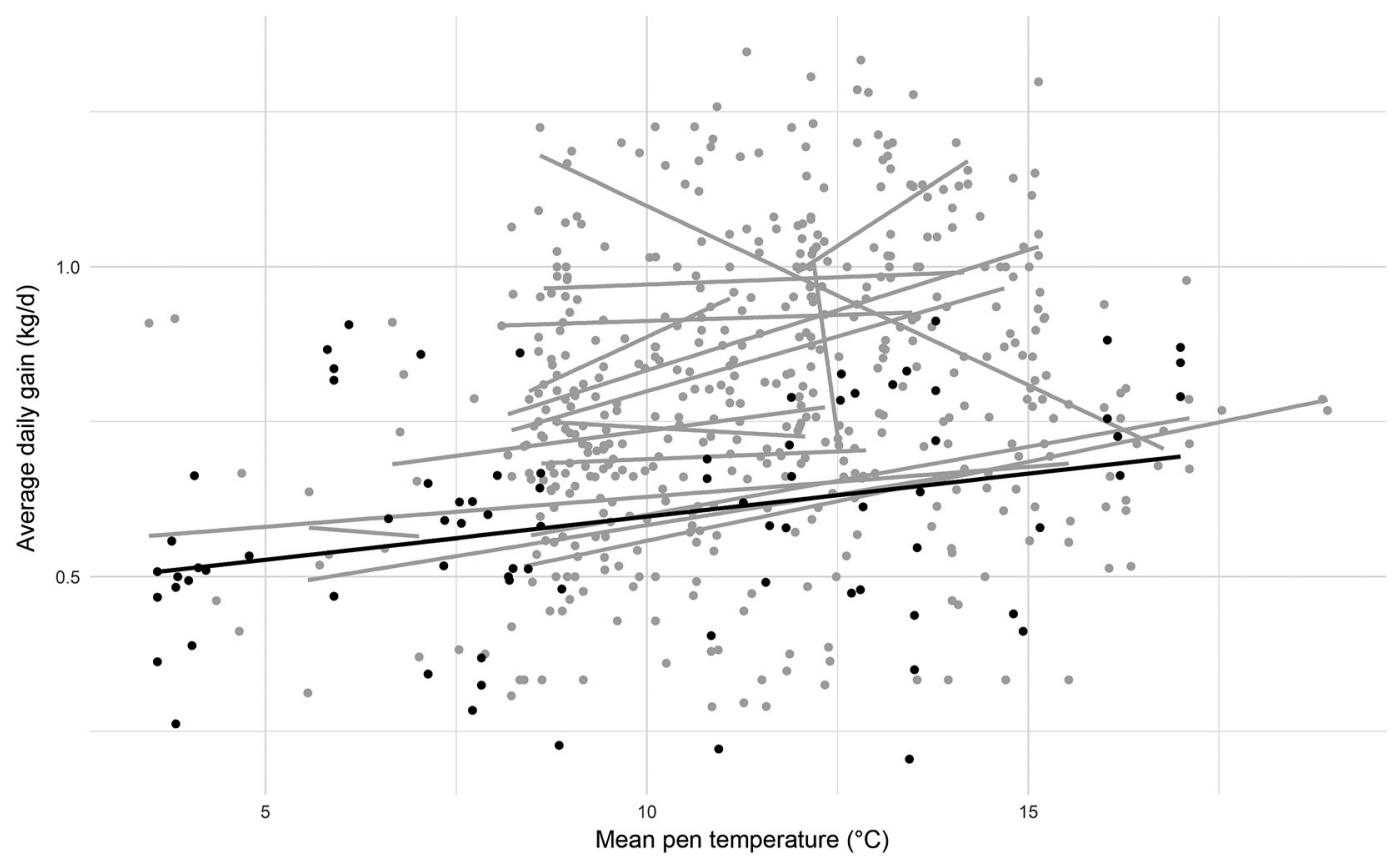

Figure 4. Descriptive summary of associations between mean pen temperature $\left({ }^{\circ} \mathrm{C}\right)$ and $\mathrm{ADG}(\mathrm{kg} / \mathrm{d})$ for 484 calves from 16 farms on the previous trial (gray) and the 79 calves from the single farm on the current trial (black). Points represent individual calves and lines represent a linear regression line for each farm. 


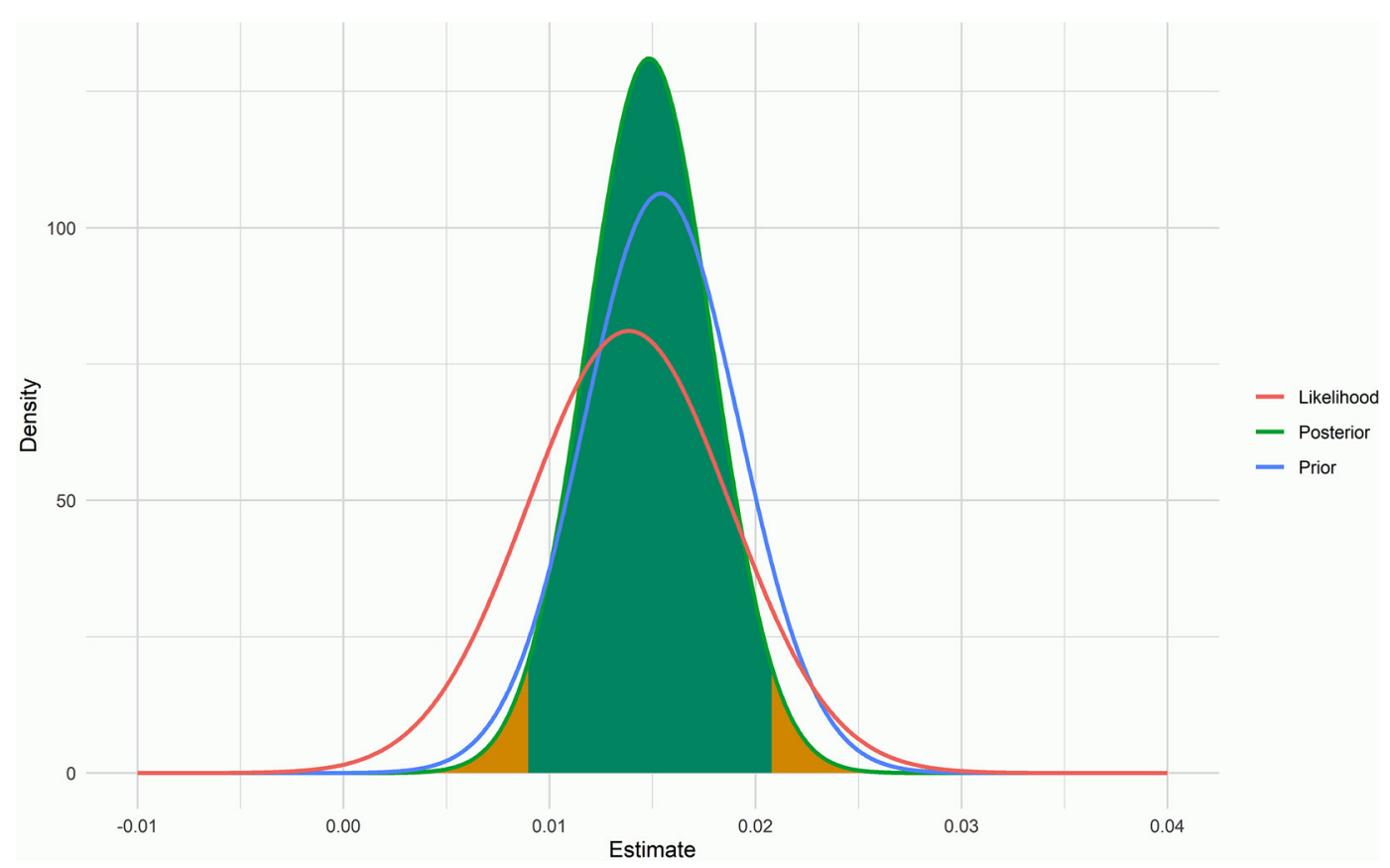

Figure 5. Descriptive presentation of prior, likelihood, and posterior estimates of associations between a $1^{\circ} \mathrm{C}$ increase in pen temperature and ADG $(\mathrm{kg} / \mathrm{d})$. The shaded area represents the $95 \%$ credible intervals for the posterior distributions.

2021). The relatively low Bayesian $R^{2}$ for associations between growth rates and environmental temperatures (0.11) suggested there are other factors associated with ADG in addition to the effect of environmental temperatures demonstrated in the current study.

\section{CONCLUSIONS}

Results from this RCT demonstrated that 1-kW heat lamps had a significant positive impact on the ADG of preweaning calves on dairy farms during colder periods. Environmental temperature was positively associated with ADG in calves during colder periods, which was reinforced when prior information from previous research was integrated through a Bayesian modeling approach. This represents an important factor for consideration in the improvement of productivity of calves on dairy farms.

\section{ACKNOWLEDGMENTS}

This research was carried out as part of a wider calf health research project funded by the Agricultural and Horticulture Development Board (AHDB; Warwickshire, UK), the AgriFood Charities Partnership (Bedford, UK), and the University of Nottingham School of Veterinary Medicine and Science (Leicestershire, UK). The authors thank the farm staff involved in this trial, as this research would not be possible without their contributions and commitment. The authors have not stated any conflicts of interest.

\section{REFERENCES}

Archer, S. C. 2021. An observational study of growth rate and body weight variance partition for United Kingdom dairy calves from birth to 20 weeks of age. JDS Commun. 2:248-252. https://doi .org/10.3168/jdsc.2020-0068.

Barton, K. 2020. 'MuMIn: Multi-Model Inference', R package version 1.43.17. Accessed Jan. 20, 2022. https://cran.r-project.org/ package $=$ MuMIn.

Bhat, S. A., B. Bhushan, S. A. Sheikh, T. Chandrasekar, A. S. Godara, P. Bharti, and K. P. Japheth. 2015. Effect of infrared lamps to ameliorate cold stress in Vrindavani calves. Vet. World 8:777-782. https://doi.org/10.14202/vetworld.2015.777-782.

Borderas, F. T., A. M. B. de Passillé, and J. Rushen. 2009. Temperature preferences and feed level of the newborn dairy calf. Appl. Anim. Behav. Sci. 120:56-61. https://doi.org/10.1016/j.applanim .2009.04.010.

Chung, J. H., and Y. Lim. 2019. BDEsize: Efficient Determination of Sample Size in Balanced Design of Experiments. R package version 1.2. Accessed Jan. 20, 2022. https://cran.r-project.org/web/ packages/BDEsize/index.html.

Collier, R. J., D. K. Beede, W. W. Thatcher, L. A. Israel, and C. J. Wilcox. 1982. influences of environment and its modification on dairy animal health and production. J. Dairy Sci. 65:2213-2227. https://doi.org/10.3168/jds.S0022-0302(82)82484-3.

Dohoo, I. R., S. W. Martin, and H. Stryhn. 2009. Veterinary Epidemiologic Research. VER Inc.

Earley, B., M. Murray, J. A. Farrell, and M. Nolan. 2004. Rearing calves outdoors with and without calf jackets compared with indoor housing on calf health and live-weight performance. Ir. J. Agric. Food Res. 43:59-67.

Gelman, A., B. Goodrich, J. Gabry, and A. Vehtari. 2019. R-squared for Bayesian regression models. Am. Stat. 73:307-309. https://doi .org/10.1080/00031305.2018.1549100. 
Goodrich, B., J. Gabry, I. Ali, and S. Brilleman. 2020. 'rstanarm: Bayesian applied regression modeling via Stan', R package version 2.21.1. Accessed Jan. 20, 2022. https://mc-stan.org/rstanarm.

Hyde, R., M. J. Green, V. E. Sherwin, C. Hudson, J. Gibbons, T. Forshaw, M. Vickers, and P. M. Down. 2020. Quantitative analysis of calf mortality in Great Britain. J. Dairy Sci. 103:2615-2623. https: //doi.org/10.3168/jds.2019-17383.

Hyde, R., M. J. Green, C. Hudson, and P. M. Down. 2021. Factors associated with daily weight gain in preweaned calves on dairy farms. Prev. Vet. Med. 190:105320. https://doi.org/10.1016/j .prevetmed.2021.105320.

Kuhn, M., and H. Wickham. 2020. Tidymodels: A collection of packages for modeling and machine learning using tidyverse principles. R package. Accessed Jan. 20, 2022. https://www.tidymodels.org.

Lago, A., S. M. McGuirk, T. B. Bennett, N. B. Cook, and K. V. Nordlund. 2006. Calf respiratory disease and pen microenvironments in naturally ventilated calf barns in winter. J. Dairy Sci. 89:40144025. https://doi.org/10.3168/jds.S0022-0302(06)72445-6.

Montgomery, A. A., T. J. Peters, and P. Little. 2003. Design, analysis and presentation of factorial randomised controlled trials. BMC Med. Res. Methodol. 3:26. https://doi.org/10.1186/1471-2288-3 -26 .

Muth, C., Z. Oravecz, and J. Gabry. 2018. User-friendly Bayesian regression modeling: A tutorial with rstanarm and shinystan. Accessed Jan. 20, 2022. https://www.tqmp.org/RegularArticles/ vol14-2/p099/.

Nonnecke, B. J., M. R. Foote, B. L. Miller, M. Fowler, T. E. Johnson, and R. L. Horst. 2009. Effects of chronic environmental cold on growth, health, and select metabolic and immunologic responses of preruminant calves. J. Dairy Sci. 92:6134-6143. https://doi.org/10 $.3168 /$ jds.2009-2517.

Nordlund, K. V. 2008. Practical considerations for ventilating calf barns in winter. Vet. Clin. North Am. Food Anim. Pract. 24:41-54. https://doi.org/10.1016/j.cvfa.2007.10.006.

Piccione, G., G. Caola, and R. Refinetti. 2003. Daily and estrous rhythmicity of body temperature in domestic cattle. BMC Physiol. 3:7. https://doi.org/10.1186/1472-6793-3-7.

R Core Team. 2020. R: A Language and Environment for Statistical Computing. https://www.r-project.org/.

Robinson, D., A. Hayes, and S. Couch. 2021. broom: Convert Statistical Objects into Tidy Tibbles. $\mathrm{R}$ package version 0.7.4. Accessed Jan. 20, 2022. https://cran.r-project.org/package=broom.

Roland, L., M. Drillich, D. Klein-Jöbstl, and M. Iwersen. 2016. Invited review: Influence of climatic conditions on the development, performance, and health of calves. J. Dairy Sci. 99:2438-2452. https: //doi.org/10.3168/jds.2015-9901.
Scoley, G., A. Gordon, and S. J. Morrison. 2019. The effect of calf jacket usage on performance, behaviour and physiological responses of group-housed dairy calves. Animal 13:2876-2884. https://doi.org/ 10.1017/S1751731119001071.

Shivley, C. B., J. E. Lombard, N. J. Urie, C. A. Kopral, M. Santin, T. J. Earleywine, J. D. Olson, and F. B. Garry. 2018. Preweaned heifer management on US dairy operations: Part VI. Factors associated with average daily gain in preweaned dairy heifer calves. J. Dairy Sci. 101:9245-9258. https://doi.org/10.3168/jds.2017-14022.

Sibbald, B., and M. Roland. 1998. Understanding controlled trials. Why are randomised controlled trials important? BMJ 316:201. https://doi.org/10.1136/bmj.316.7126.201.

Spiegelhalter, D. J., K. R. Abrams, and J. P. Myles. 2004. Bayesian Approaches to Clinical Trials and Health-Care Evaluation. John Wiley \& Sons Ltd.

UK Government. 2021. Gas and electricity prices in the non-domestic sector - GOV.UK. Accessed Jun. 23, 2021. https://www.gov.uk/ government/statistical-data-sets/gas-and-electricity-prices-in-the -non-domestic-sector.

Urie, N. J., J. E. Lombard, C. B. Shivley, C. A. Kopral, A. E. Adams, T. J. Earleywine, J. D. Olson, and F. B. Garry. 2018. Preweaned heifer management on US dairy operations: Part V. Factors associated with morbidity and mortality in preweaned dairy heifer calves. J. Dairy Sci. 101:9229-9244. https://doi.org/10.3168/jds .2017-14019.

Wickham, H., M. Averick, J. Bryan, W. Chang, L. McGowan, R. Francois, G. Grolemund, A. Hayes, L. Henry, J. Hester, M. Kuhn, T. Pedersen, E. Miller, S. Bache, K. Müller, J. Ooms, D. Robinson, D. Seidel, V. Spinu, K. Takahashi, D. Vaughan, C. Wilke, K. Woo, and H. Yutani. 2019. Welcome to the Tidyverse. J. Open Source Softw. 4:1686. https://doi.org/10.21105/joss.01686.

Windeyer, M. C., K. E. Leslie, S. M. Godden, D. C. Hodgins, K. D. Lissemore, and S. J. LeBlanc. 2014. Factors associated with morbidity, mortality, and growth of dairy heifer calves up to 3 months of age. Prev. Vet. Med. 113:231-240. https://doi.org/10.1016/j .prevetmed.2013.10.019.

\section{ORCIDS}

Robert M. Hyde ๑ https://orcid.org/0000-0002-8705-9405 Martin J. Green ํㅜ https://orcid.org/0000-0002-6408-6443 Chris Hudson @ \ttps://orcid.org/0000-0003-4777-062X

Peter M. Down ๑ https://orcid.org/0000-0003-1896-7255 